\title{
Intraoperative requirement of Phenylephrine for spinal anaesthesia, with comparison of hemodynamic parameters between severe pre-eclamptic and normotensive parturients for elective caesarean section: A prospective study
}

\author{
Leena Goel $^{1, *}$, Rina Cordeiro ${ }^{2}$, Megha Goel ${ }^{3}$ \\ ${ }^{1}$ Assistant Professor, ${ }^{2}$ Senior Resident, ${ }^{3}$ Intern, Dept. of Anaesthesia, Goa Medical College, Goa, Maharashtra, India
}

*Corresponding Author:

Email: drhcgoel@gmail.com

Received: $12^{\text {th }}$ May, 2017

Accepted: 02 ${ }^{\text {nd }}$ September, 2017

\begin{abstract}
Aim: The aim of this study is to assess the efficacy and safety of spinal anaesthesia by comparing the severity of hypotension and intraoperative requirement of Phenylephrine to treat it in severe pre-eclamptic and normotensive parturients undergoing elective caesarean section.

Materials and Methods: A total of 50 parturients, 25 each of normotensive and pre-eclamptic were given spinal anaesthesia with $12.5 \mathrm{mg}$ of hyperbaric bupivacaine after preloading with $10 \mathrm{ml} / \mathrm{kg}$ of Ringer lactate solution. The vitals namely heart rate (HR), systolic blood pressure (SBP), diastolic blood pressure (DBP), and the mean arterial blood pressure (MAP) were monitored during caesarean section. Severity of hypotension and the mean requirement of Phenylephrine to manage this hypotension were compared in the two groups. Foetal outcome was compared in two groups by studying the Apgar score.

Results: There was statistically less hypotension following spinal anaesthesia and less requirement of vasopressor in preeclamptic as compared to normotensive parturients. The mean requirement of Phenylephrine was $156.3 \pm 62 \mu$ in normotensive (group I) and comparatively more than the requirements of pre-eclamptic (group II) parturients and was statistically significant $(\mathrm{p}<0.05)$. The Apgar score at 1 and 5 minutes were equal in both the groups.

Conclusion: Spinal anaesthesia is ideal and safe option for severe pre eclamptics undergoing elective caesarean section without any additional risk to baby.
\end{abstract}

\section{Introduction}

Pre-eclampsia in severe form creates risks for the parturient and fetus. The reported incidence of preeclampsia in obstetrics practice is $5-7 \% .^{1}$ Its management and optimisation is an arduous task both for the obstetrician and anaesthesiologist. Provision of safe anaesthesia and perioperative hemodynamic stability is a challenge in these patients undergoing the surgery of caesarean section. ${ }^{2}$ The potential complications of general anaesthesia, such as hypertensive crisis, ${ }^{3}$ stroke, ${ }^{4}$ and difficult airway management, ${ }^{5}$ have been reported as the leading causes of morbidity and mortality in the pre-eclamptic population. The pervasive belief that sympathetic blockade following neuraxial anaesthesia may cause hypotension with resulting decreased uteroplacental perfusion can be calamitous to mother and fetus, has prevented the widespread use of spinal anaesthesia in these patients. Spinal anaesthesia is favourable in pregnancy with enhancement of uteroplacental blood flow and attenuates serum catecholamines level. The benefits extend to pre-eclamptics with diminishment of uteroplacental resistance and favours intervillous blood flow. If SBP maintains $>80 \%$ of baseline then the Apgar scores and umbilical artery $\mathrm{pH}$ are undeterred in preeclampsia. ${ }^{6}$ A number of studies have been conducted to find the hemodynamic effects of regional anaesthesia in patients with preeclampsia. Present study is planned to study the intraoperative hypotension and
Phenylephrine requirement in patients undergoing elective caesarean section under spinal anaesthesia with severe preeclampsia when compared with normotensive patients.

\section{Material and Methods}

This prospective study was conducted in 50 parturients after approval from our institution's ethics committee. Informed consents were obtained from all the parturients. The patients were grouped as group I (normal parturients) and group II (with severe preeclampsia). The decided sample size of 50 patients was arrived based on power analysis performed after a pilot study to detect mean difference of MAP of 4 units (mean difference $=4$ units, SD $= \pm 5$ units). The required sample size with $95 \%$ confidence and power of $80 \%$ was 25 patients to be recruited for group I and 25 patients for group II.

Inclusion criteria: Patients in the age group of 18-30 years with singleton pregnancy scheduled for elective caesarean section were included in the study.

Exclusion criteria: Patients with obesity (BMI >35 $\mathrm{kg} / \mathrm{m}^{2}$ ), acute fetal distress, chronic hypertension, placenta previa, diabetes mellitus, coagulopathy, multiple pregnancy, renal and cardiac disease and with refusal for spinal anaesthesia were not included in the study.

In operation room patients were wheeled and intravenous $18 \mathrm{G}$ cannula was inserted. The preloadings 
of the patients were done with $10 \mathrm{ml} / \mathrm{kg}$ Ringer Lactate Solution. Intravenous Ranitidine $50 \mathrm{mg}$ and Metoclopramide $10 \mathrm{mg}$ were given 20 minutes prior to surgery. This was standardised for both groups. All preeclamptic parturients were on Methyldopa 250mg three times a day or Labetetol $800-1200 \mathrm{mg}$ in 2 to 3 divided doses or Nifedipine 10-20 mg two to three times a day. Non Invasive Blood Pressure (NIBP), electro cardiogram (ECG), Heart Rate (HR), Oxygen saturation $\left(\mathrm{SpO}_{2}\right)$, Systolic Blood Pressure (SBP), Diastolic Blood Pressure (DBP) and Mean Arterial Pressure (MAP) were recorded before administration of spinal anaesthesia to serve as base line parameters. Intraoperatively readings were taken every 2 minutes for the first 30 minutes and thereafter every 5 minutes till the end of surgery.

Spinal Anaesthesia was administered in sitting position with aseptic precautions using a $25 \mathrm{G}$ Quinkes Babcock's needle at $\mathrm{L}_{3}-\mathrm{L}_{4}$ interspace with $12 \mathrm{mg}$ of $0.5 \%$ hyperbaric Bupivicaine and $20 \mu \mathrm{g}$ fentanyl. Patients were immediately put in supine position and a wedge was placed under the right buttock for left uterine displacement to avoid aorto-caval compression. Surgery was started once $T_{6}$ level of anaesthesia was achieved. Infusion of Ringers Lactate was continued at $5 \mathrm{ml} / \mathrm{kg} / \mathrm{hr}$. The Apgar score was noted at 1 and 5 minutes after delivery of baby. The infusion of $20 \mathrm{U}$ of Oxytocin in $500 \mathrm{ml}$ Ringers Lactate was started at the rate of $5 \mathrm{ml} / \mathrm{min}$ until the uterus retracted and thereafter continued at the rate of $1-2 \mathrm{ml} / \mathrm{min}^{7}$

Hypotension was defined as MAP $<20 \%$ from baseline or SBP $<100 \mathrm{~mm}$ of $\mathrm{Hg}$ and was treated with $50 \mu \mathrm{g}$ Phenylephrine IV bolus, repeated at 10 minutes interval if required. The total amount of Phenylephrine required was noted. Bradycardia $(\mathrm{HR}<60 / \mathrm{min})$ was treated with $0.6 \mathrm{mg}$ IV atropine (maximum $1.8 \mathrm{mg}$ ).

\section{Statistical Analysis}

The Student (unpaired) $t$ test was used to detect significant difference of mean in independent samples and Chi square test was used for difference of proportions. $\mathrm{p}<0.05$ was considered significant. Data were expressed as mean $\pm \mathrm{SD}$ (Standard Deviation).The mean and standard deviation was derived using Statistical Package for Social Sciences(SPSS) version 14 .

\section{Results}

The two groups had no statistical significant difference as far as age, weight, height and period of gestation was concerned and were comparable (Table1). The baseline heart rate and subsequent changes remained comparable in both groups and the difference were statistically insignificant.

The SBP, DBP and MAP at baseline were elevated in pre-eclamptic (group II) as compared to normotensive (group I) patients.

Following the administration of spinal anaesthesia the hemodynamic parameters i.e. SBP, DBP and MAP were lowered from baseline in both groups. However the minimum observed readings of SBP, DBP and MAP were $124 \pm 6 \mathrm{mmHg}, 83 \pm 5 \mathrm{mmHg} 96 \pm 8 \mathrm{mmHg}$ respectively in normotensive group I which were more lower than that of pre-eclamptic group II, $157 \pm 12,109 \pm 17,119 \pm 11 \mathrm{mmHg}$ respectively and were statistically significant $(\mathrm{p}<0.05)$ as shown in (Fig. 1).

The mean requirement of Phenylephrine was $156.3 \pm 62 \mu \mathrm{g}$ in normotensive (group I) and comparatively more than $52.1 \pm 34.31 \mu \mathrm{g}$, the requirements of pre-eclamptic (group II) parturients and was statistically significant $(\mathrm{p}<0.05)$. The Apgar score at 1 and 5 minutes were equal in both the groups.

Table 1: showing Mean \pm SD for selected variables

\begin{tabular}{|l|c|c|c|}
\hline \multicolumn{1}{|c|}{ Parameter } & $\begin{array}{c}\text { Group 1 } \\
\text { N=25 }\end{array}$ & $\begin{array}{c}\text { Group 2 } \\
\text { N=25 }\end{array}$ & P-value \\
\hline Age(years) & $25 \pm 4$ & $23 \pm 5$ & $>0.05(\mathrm{NS})$ \\
\hline Weight(kg) & $64.12 \pm 6.8$ & $62.41 \pm 5.9$ & $>0.05(\mathrm{NS})$ \\
\hline Height(cm) & $157.29 \pm 2.9$ & $156.91 \pm 2.3$ & $>0.05(\mathrm{NS})$ \\
\hline $\begin{array}{l}\text { APGAR Score- } \\
-1 \text { minute } \\
-5 \text { minute }\end{array}$ & $7.9 \pm 1.2$ & $7.7 \pm 1.6$ & $>0.05(\mathrm{NS})$ \\
\hline Pulse Rate(bpm) & $8.6 \pm 0.6$ & $9.3 \pm 0.5$ & $>0.05(\mathrm{NS})$ \\
\hline $\begin{array}{l}\text { Systolic Blood } \\
\text { Pressure(mm of Hg) }\end{array}$ & $124 \pm 6$ & $86 \pm 18$ & $>0.05(\mathrm{NS})$ \\
\hline $\begin{array}{l}\text { Diastolic Blood } \\
\text { Pressure(mm of Hg) }\end{array}$ & $83 \pm 5$ & $157 \pm 12$ & $<0.05(\mathrm{~S})$ \\
\hline $\begin{array}{l}\text { Mean Arterial Blood } \\
\text { Pressure(mm of Hg) }\end{array}$ & $96 \pm 8$ & $119 \pm 11$ & $<0.05(\mathrm{~S})$ \\
\hline Phenylephrine(ug) & $156.3 \pm 62$ & $52.1 \pm 34.31$ & $<0.05(\mathrm{~S})$ \\
\hline
\end{tabular}




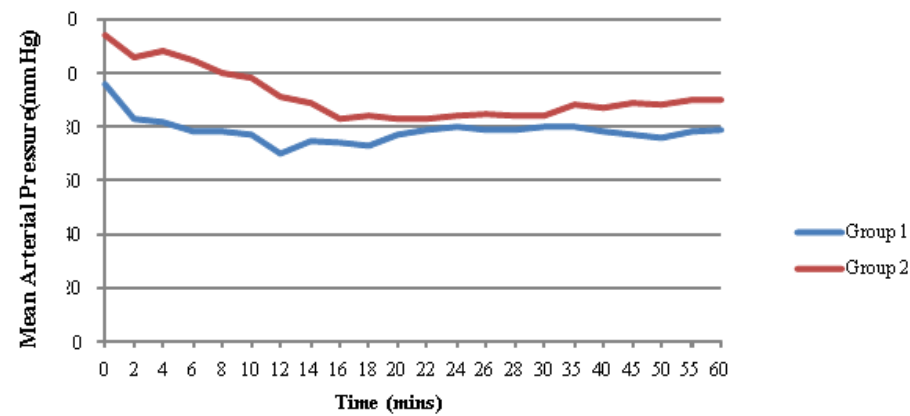

\section{Fig. 1: Comparison of Mean Arterial Pressure}

\section{Discussion}

Anaesthesiologists apprehend the administration of spinal anaesthesia in severe pre-eclamptics undergoing caesarean section as it causes serendipitous hypotension following sympathetic block. Nevertheless several authors of various studies have used spinal anaesthesia safely in pre-eclamptics resulting in favourable maternal and neonatal outcomes. ${ }^{8}$ Aya et al. observed that the risk of hypotension was almost six times less in patients with severe pre-eclampsia than in normotensive parturients. ${ }^{9}$ Another study Dyer et al. found that preeclampsia patients had a lower susceptibility to hypotension and less impairment of cardiac output than healthy parturients after sub-arachnoid block (SAB) for caesarean section. ${ }^{10}$ Spinal anaesthesia is a preferred anaesthetic technique as it is simple to perform, is rapid in onset and has a high success ratio, and provides excellent post-operative analgesia when intrathecal opioids are used. ${ }^{11,12}$

Although the results of present study were akin to Khatri et al. ${ }^{13}$ yet it was distinctive as we added $20 \mu \mathrm{g}$ Fentanyl as an adjuvant to prolong the neuraxial blockade and our choice of vasopressor was Phenylephrine unlike ephedrine as used by them. Fentanyl was chosen as an adjuvant homologous to study of Siddiqui et al. ${ }^{14}$

In the present study we compared the heart rate, the SBP, DBP and MAP after spinal anaesthesia in normotensive and severely pre-eclamptic parturients undergoing caesarean section and the Phenlyephrine requirements for managing hypotension in the same. After induction, the blood pressure decreased in both groups from the baseline, but the minimum heart rate, SBP, DBP, and MAP observed was more in the preeclamptic group as contrasted to the normotensive group, and the result was statistically significant ( $<<$ 0.05).The augmented levels of vasodilators like prostaglandins and nitric oxide are attributed to excessive hypotension after spinal anaesthesia in normotensive parturients. ${ }^{15}$ The rationale explaining the lesser drop in blood pressures in pre-eclampsia following neuraxial blockade is that there are elevated levels of endogenous vasopressors like thromboxane and endothelins which maintain vascular tone unlike that in normotensive parturients. ${ }^{16,17}$ The mean Phenylephrine requirement to treat hypotension for normotensive group $(156.3 \pm 62)$ was greater than that of the pre-eclamptic group $(52.1 \pm 34.3)$ which is statistically significant $(\mathrm{p}<0.05)$. Apgar score at 1 and 5 minutes were equal in both groups.

Various studies by Visalputra et al. and Kreerath et al. concluded that degree of hypotension and requirement of Vasopressors was similar in two groups of patients administered either SAB or epidural anaesthesia(EA) ${ }^{18,2}$ In a study by Chiu et al. also found that safety of SAB in pre-eclamptics. ${ }^{19}$ The ideal vasopressor should have quick onset, short duration, can be titrated and used prophylactically without side effects for mother and fetus. ${ }^{20}$ Phenylephrine is a selective $\alpha_{1}$ receptor agonist with immediate onset and has a short duration of action of 5-10 minutes. ${ }^{21}$ It causes marked arterial vasoconstriction and is hence utilized for managing hypotension in subarachnoid block. Although there is reflex bradycardia due to negative chronotropism, the fetus is not affected adversely. ${ }^{22}$ It has been concluded in various studies comparing Phenylephrine and ephedrine that, neonates of mothers receiving Phenylephrine have higher umbilical artery $\mathrm{pH}$ values. ${ }^{23} \mathrm{We}$ chose Phenylephrine as our vasopressor as it has lesser effects on $\mathrm{pH}$ than ephedrine. Although Phenylephrine causes increase in resistance of uterine artery, the fetal oxygen balance is maintained hence it is more favourable than ephedrine. ${ }^{24}$

Our study had limitations as we included only elective caesarean deliveries. Also the $\mathrm{pH}$ of umbilical artery was not analyzed due to financial constraint.

\section{Conclusion}

Severe pre-eclamptics have lesser incidents of hypotension under spinal anaesthesia than normotensives and requirements of Phenylephrine as vasopressor is also less.

\section{References}

1. Steegers EA, von Dadelszen P, Duvekot JJ, Pijnenborg R. Preeclampsia. Lancet 2010;376:631-44.

2. Kreerath $\mathrm{K}$ and Cronje L.Observational study of choice of anaesthesia and outcome in patients with severe pre- 
eclampsia who present for emergency Caesarean section. South Afr J Anaesth Analg 2012;18(4):206-12.

3. Henke VG, Bateman BT, Leffert LR. Spinal Anesthesia in Severe Preeclampsia. Anesth Analg 2013;117:686-93.

4. Bateman BT, Schumacher HC, Bushnell CD, PileSpellman J, Simpson LL, Sacco RL, Berman MF. Intracerebral hemorrhage in pregnancy: frequency, risk factors, and outcome. Neurology 2006;67:424-9.

5. Munnur U, de Boisblanc B, Suresh MS. Airway problems in pregnancy. Crit Care Med 2005;33:S259-68.

6. Ankichetty SP, Chin KJ, Chan VM, Sahajanandan R, Tan H, Grewal H, Perlas A. Regional anaesthesia in patients with pregnancy induced hypertension $\mathrm{J}$ Anaesthesiol Clin Pharmacol 2013;29(4):435-44.

7. Devikarani, Harsoor SS. Are we using the right dose of Oxytocin? Indian J Anaesth 2010;54:371-3.

8. Chaudhary S, Salhotra R. Subarachnoid block for caesarean section in severe preeclampsia.J Anaesthesiol Clin Pharmacol 2011;27(2):169-73.

9. Aya AG, Mangin R, Vialles N, Ferrer JM, Robert C, Ripart J, de La Coussaye JE. Patients with severe preeclampsia experience less hypotension during spinal anaesthesia for elective caesarean delivery than healthy parturients: A prospective cohort comparison. Anesth Analg 2003;97:867-72.

10. Dyer RA, Piercy JL, Reed AR. The role of the anaesthetist in the management of the pre-eclamptic patient. Curr Opin Anaesthesiol 2007;20:168-74.

11. Sia AT, Fun WL, Tan AU. The ongoing challenges of regional and general anaesthesia in obstretrics . Best Pract Res Clin Obstet Gynaecol 2010;24:303-12.

12. Gogarten W. Spinal anaesthesia for obstretics. Best Pract Res Clin Obstet Gynaecol 2003;17:377-92.

13. Khatri RK,Sethi P, Ujawal S. Perioperative hemodynamic response and vasopressor requirement during spinal anaesthesia for caesarean section in healthy and severe pre-eclamptic parturients:a prospective cohort comparison. Anaesth Pain \& Intensive Care 2014;18(2):152-6.

14. Siddiqui AS, Salim B, Siddiqui SZ. Comparison of Phenylephrine and ephedrine for treating hypotension after spinal anaesthesia for caesarean section: A Randomized double-blind clinical trial. Anaesth Pain \& Intensive Care 2015;19(1):44-9.

15. Hashmi M. Low pressure headache in early pregnancy with dramatic response to glucocorticoids:a case report.J Med Case Resp 2014;8(1):115.

16. Redman CW, Sargent IL.Pre-eclampsia,the placenta and the maternal systemic inflammatory response:A review. Placenta 2003;24:521-7.

17. Santos AC, Birnbach DJ. Spinal anaesthesia in parturients with severe preeclamsia: time for consideration. Anesth Analg 2003;97:621-2.

18. Visalyaputra S, Rodanant $\mathrm{O}$, Somboonviboon W, Tantivitayatan K, Thienthong S, Saengchote W. Spinal versus epidural anaesthesia for caesarean delivery in severe preeclampsia: A prospective randomized, multicenter study. AnesthAnalg. 2005; 101(3):862-8.

19. Chiu IU, Mansor M, Ng KP, Chan YK. Retrospective review of spinal versus epidural anaesthesia for caesarean section in pre-eclamptic patients. Int J Obstet Anesth 2003;12:17-23.

20. Simin A, Zahra F, Pouya HM, Reza T. Comparison the effect of ephedrine and Phenylephrine in treatment of hypotension after spinal anaesthesia during caesarean section. Open J Obst and Gynaecol 2012;2:192-6.

21. Westfall TC, Westfall DP. Adrenergic agonists and antagonists. In: Brunton LL, Lazo JS, Parker KL, editors. Goodman and Gilman's: The Pharmacological Basis of Therapeutics. 11 th ed. New York: McGraw Hill;2006. pp. 237-95.

22. Stewart A, Fernando R, McDonald S, Hignett R, Jones T, Columb M. The dose-dependent effects of Phenylephrine for elective caesarean delivery under spinal anaesthesia. Anesth Analg 2010;111:1230-37.

23. Lee A, Nagn Kee WD, Gin T. A quantitative systemic review of randomised controlled of ephederine versus Phenylepherine for the management of hypotension during spinal anaesthesia foe caesarean deliveries. Anesth Analg 2002;94:920-6.

24. Macarthur A, Riley ET. Obstetric Anesthesia controversies: Vasopressor choice for post spinal hypotension during caesarean deliveries. Int Anesthesiol Clin 2007;45:115-32. 